\title{
KẾT QUẢ PHẪU THUẬT KÉN PHẾ QUẢN TẠI BỆNH VIỆN PHỔI TRUNG ƯƠNG TỪ NĂM 2011 ĐẾN NĂM 2015
}

Khiếu Mạnh Cường*, Nguyễn Lê Vinh*, Nguyễn Sỹ Khánh*, Đinh Văn Lương *, Đoàn Quốc Hung**

\section{TÓM TÁ̀T}

Kén phế quản là một dị tật bẩm sinh của phổi, cần được chẩn đoán và phẫu thuật sớm. Từ năm 2011 đến năm 2015 có 44 trường hợp (19 nam, 25 nữ) sau phẫu thuật có kết quả mô bệnh học là kén phế quản, độ tuổi trung bình 41,86 tuổi. Triệu chứng chủ yếu ho, ho máu, đau ngực, khó thở, sốt. Hình ảnh trên phim XQuang ngực thường quy và CT scanner ngực chủ yếu: kén khí, kén có mức dịch khí, khối mờ đều, khối mờ trong kén khí. Kén phế quản trong phổi tổn thương bên phải chiếm ưu thế, trong khi đó kén phế quản trung thất chủ yếu ở ngực trái. Điều trị chủ yếu là phẫu thuật, với kén phế quản trung thất cắt kén, trong khi đó kén phế quản trong phổi chủ yếu cắt thùy phổi chứa kén phế quản. Biến chứng trong mổ, sớm ngày đầu sau mổ ít, trong khi đó biến chứng sau mổ muộn hơn thường nhẹ và xử lý đơn giản chủ yếu ổ dịch khí khu trú. Thời gian nằm viện sau mổ trung bình 16,39 ngày.

Tù khóa: Kén phế quản

\section{SUMMARY}

RESULTS OF BRONCHOGENIC CYSTS SURGERY AT THE NATIONAL LUNG HOSPITAL FROM 2011 TO 2015

Bronchogenic cysts is a congentinal pulmonary malformation and it needs to be diagnosed and treated early. 44 cases at the National Lung Hospital from 2011 to 2015 were establish diagnosis based on postoperation on histologic examination and performed an analysis: sex ratio male/female: 19/25. Mean age: 41,86 . Clinical signs were cough, fever, pain and dyspnea, hemoptysis. Images in Xray and CTscanner were bullae, hemogenous shadow, bullae within fluid level, hemogenous shadow in the bullae. Intrapulmonary bronchogenic cysts was dominant on the right side, and mediastinal bronchogenic cyst was dominant on the left side. Surgical procedure of bronchogenic cysts composed: lobectomy with intrapulmonary bronchogenic cyst and surgical excision of the cyst in the mediastinum was approached. Postoperative complications are common seen: air or fluid in plueral cavity. Postoperative hospital days was 16,39 days.

Keyword: Bronchogenic cysts.

\section{I. ĐẶT VẤN ĐỀ}

Sự phát triển bất thường của mầm phổi trong thời kỳ bào thai xảy ra từ ngày thứ 26 đến ngày thứ 40 của thai kỳ (tức từ tuần thứ 4 đến tuần thứ 6 của thai kỳ) hình thành nên một số dị tật bẩm sinh của phế quản và phổi như: kén phế quản, dị dạng nang tuyến bảm sinh, khí phế thũng, phổi biệt lập,...

Kén phế quản là một trong những dị tật bẩm sinh hiếm gặp của phổi, có thể được chẩn đoán trước sinh, ở trẻ sơ sinh hoặc trẻ nhỏ bởi vì các triệu chứng chèn ép cơ quan lân cận. Ở người lớn thường được chẩn đoán khi chụp phim XQuang phổi kiểm tra sức khỏe hoặc có biến chứng: viêm nhiễm, đau ngực, khó thở, vỡ kén, ho máu.

Vị trí kén phế quản có thể ở trong nhu mô phổi, rãnh phổi, trung thất,... Bình thường kén phế quản không thông với cây phế quản nhưng khi có bội nhiễm kén sẽ thông với phế quản tạo

* Bệnh viện Phổi Trung uong,

** Bệnh viện Việt Đúcc- Đại học Y Hà Nội

Người chịu trách nhiệm khoa học: PGS.TS. Đoàn Quốc Hung

Ngày nhận bài: 01/05/2018 - Ngày Cho Phép Đăng: 20/05/2018

Phản Biện Khoa học: GS.TS. Bùi Đức Phú

PGS.TS. Đặng Ngọc Hùng 
hình mức nước - hơi. Do vậy, trên lâm sàng bệnh nhân sẽ có những đợt nhiễm trùng tái diễn với triệu chứng hay gặp là ho khạc đờm, sốt, ho ra máu,...và dễ chẩn đoán điều trị sang các bệnh khác.

Triệu chứng lâm sàng của kén phế quản không đặc hiệu nên chẩn đoán kén phế quản chủ yếu dựa vào chẩn đoán hình ảnh: XQuang phổi thường quy, đặc biệt chụp cắt lớp vi tính, nhưng việc chẩn đoán chính xác trước mổ còn hạn chế. Điều trị triệt để duy nhất bằng phẫu thuật: cắt bỏ kén hoặc cắt thùy phổi hay phần thùy phổi chứa kén phế quản.

Việc chẩn đoán và điều trị sớm kén phế quản là cần thiết để hạn chế những biến chứng không mong muốn có thể xảy ra, bởi vậy mục đích chúng tôi tiến hành đề tài “Đánh giá kết quả phẫu thuật kén phế quản tại Bệnh viện Phổi Trung ương từ năm 2011 đến năm 2015" với 2 mục tiêu sau:

- Nhận xét một số đặc điểm lâm sàng, cận lâm sàng kén phế quản.

- Nhận xét kết quả sớm phẫu thuật kén phế quản tại bệnh viện Phổi trung uơng tù năm 2011 đến năm 2015.

\section{II. ĐỐI TƯợNG VÀ PHƯƠNG PHÁP NGHIÊN CÚU}

- 2.1. Đối tượng nghiên cứu

- 2.1.1. Đối tượng nghiên cúu

Nghiên cứu hồi cứu được tiến hành trên các bệnh nhân được chẩn đoán mô bệnh kén phế quản tại Bệnh viện Phổi Trung ương từ tháng 1 năm
2011 đến tháng 12 năm 2015.

\subsubsection{Tiêu chuẩn chọn bệnh nhân}

- Không phân biệt tuổi, giới. Có chẩn đoán giải phẫu bệnh sau mổ là kén phế quản.

- Bệnh án đầy đủ thông tin nghiên cứu.

\subsubsection{Tiêu chuẩn loại trù̀}

- Không có kết quả giải phẫu bệnh sau mổ.

- Có kết quả giải phẫu bệnh sau phẫu thuật viêm mạn tạo kén.

\subsection{Phương pháp nghiên cứu}

\subsubsection{Thiết kế nghiên cúu}

Nghiên cứu mô tả hồi cứu, mẫu thuận tiện.

\subsubsection{Phương pháp thu thập số liệu}

Khai thác thông tin hồ sơ bệnh án sẵn có điền vào mẫu bệnh án nghiên cứu.

\subsection{Phương pháp xử lý số liệu}

- Nhập số liệu bằng phần mềm Epidata. Xử lý số liệu bằng phần mềm Stata 10.0 . Các thuật toán được sử dụng là tính tỷ lệ \%, tính trung bình, độ lệch $(X \pm S D)$, các thuật toán kiểm định.

\section{KẾT QUẢ}

Nghiên cứu hồi cứu 44 trường hợp sau phẫu thuật có kết quả giải phẫu bệnh là kén phế quản từ tháng 1 năm 2011 đến tháng 12 năm 2015 cho kết quả sau:

\subsection{Phân bố tuổi, giới}

- Tuổi trung bình $41,86 \pm 11,97$, thấp nhất 15 tuổi, cao nhất 65 tuổi.

- Tỷ lệ giới tính: nam 19 trường hợp $(43,18 \%)$, nữ 25 trường hợp $(56,82 \%)$.

\subsection{Triệu chứng lâm sàng}

Bảng 1. Triệu chứng lâm sàng chủ yếu

\begin{tabular}{|c|c|c|c|c|c|c|}
\hline \multicolumn{7}{|c|}{ Triệu chứng lâm sang chủ yếu } \\
\hline & Đau ngục & Khó thơ & Ho khan & Ho máu & Đòm mủ & Sốt \\
\hline n & 29 & 16 & 12 & 17 & 14 & 12 \\
\hline$\%$ & 26.85 & 14.81 & 11.11 & 15.74 & 12.96 & 11.11 \\
\hline
\end{tabular}




\subsection{Chẩn đoán hình ảnh}

Bảng 2. Hình ảnh tổn thương và số lượng kén trên phim $X$ quang ngực

\begin{tabular}{|c|c|c|c|c|c|c|c|c|c|}
\hline & \multicolumn{6}{|c|}{ Hình ảnh kén } & \multicolumn{3}{|c|}{ Số lượng kén } \\
\hline & $\begin{array}{l}\text { Kén } \\
\text { khí }\end{array}$ & $\begin{array}{c}\text { Dịch } \\
\text { khí }\end{array}$ & $\begin{array}{l}M \grave{̀} \\
\text { đều }\end{array}$ & $\begin{array}{c}\text { Mò' } \\
\text { không } \\
\text { đều }\end{array}$ & $\begin{array}{c}\text { Khối } \\
\text { trong } \\
\text { kén }\end{array}$ & $\begin{array}{c}\text { Không } \\
\text { rõ }\end{array}$ & $\begin{array}{c}\text { Đo'n } \\
\text { kén }\end{array}$ & $\begin{array}{c}\text { Đa } \\
\text { kén }\end{array}$ & $\begin{array}{c}\text { Không } \\
\quad r \tilde{o}\end{array}$ \\
\hline $\mathbf{n}$ & 13 & 7 & 16 & 4 & 3 & 1 & 30 & 11 & 3 \\
\hline$\%$ & 29,54 & 15,90 & 36,36 & 9,09 & 6,82 & 2,27 & 68.18 & 25 & 6,82 \\
\hline
\end{tabular}

Bảng 3. Hình ảnh cắt lớp vi tính lồng ngực

\begin{tabular}{|c|c|c|c|c|c|}
\hline & \multicolumn{5}{|c|}{ Hình ảnh kén } \\
\hline & Kén khí & Dịch khí & Khối mò đều & Mò̀ không đềेu & Khối trong kén \\
\hline $\mathbf{n}$ & 9 & 10 & 16 & 1 & 8 \\
\hline$\%$ & 20,45 & 22,73 & 36,36 & 2,77 & 18,18 \\
\hline
\end{tabular}

3.4. Kết quả mô bệnh (Bảng 4)

\begin{tabular}{|l|c|c|c|}
\multirow{2}{*}{} & \multicolumn{3}{|c|}{ Giải phẫu bệnh } \\
\cline { 2 - 4 } & Kén đơn thuần & Kén bội nhiêm nấm & Kén bội nhiễm \\
\hline \% & 17 & 11 & 16 \\
\hline & 38,64 & 25,00 & 36,36 \\
\hline
\end{tabular}

\section{5. Điều trị}

- Kén phế quản trong phổi $28 / 30$ trường hợp cắt thùy phổi, 2/30 trường hợp cắt kén.

- Kén phế quản trung thất 10/11 trường hợp cắt kén, $1 / 11$ trường hợp phải cắt thùy phổi kèm theo.

- Kén phế quản phối hợp cả trung thất và phổi: $1 / 3$ trường hợp cắt nguyên kén, $2 / 3$ trường hợp cắt kén trung thất và thùy phổi chứa kén.

- Thời gian mổ trung bình: $167,6 \pm 56,36$ phút, ngắn nhất: 45 phút, lâu nhất: 300 phút.

\subsection{Biến chứng (Bảng 5)}

Trong mổ: 42 (95,45 \%) trường hợp không biến chứng, 2 (4,55%) trường hợp chảy máu.

\begin{tabular}{|l|c|c|c|c|c|}
\multicolumn{1}{|c|}{ Sau mổ } & $\begin{array}{c}\text { Chảy } \\
\text { máu }\end{array}$ & Viêm phổi & $\begin{array}{c}\text { Viêm màng } \\
\text { phổi }\end{array}$ & $\begin{array}{c}\text { Dịch/khí kéo } \\
\text { dài }\end{array}$ & $\begin{array}{c}\text { Nhiễm trùng vết } \\
\text { mồ }\end{array}$ \\
\hline n & 1 & 2 & 2 & 10 & 2 \\
\hline$\%$ & 2,27 & 4,55 & 4,55 & 22,72 & 4,55 \\
\hline
\end{tabular}

\subsection{Thời gian nằm viện sau phẫu thuật}

- Trung bình $16,39 \pm 14,03$ ngày, ngắn nhất 6 ngày, lâu nhất 85 ngày.

\subsection{Kết quả phẫu thuật}

- Tình trạng ra viện 100\% trong tình trạng lâm sang ổn định, 41 trường hợp trên phim xquang phổi nở sát thành ngực, 3 trường hợp có 
hình ảnh dày dính màng phổi.

\section{BÀN LUẬN}

\subsection{Tuổi giới}

- Tuổi: trong nghiên cứu của chúng tôi tuổi trung bình 41,86 tuổi, tương tự như tác giả: Vũ Chí Thành [1] tuổi trung bình 40 tuổi, Faten Limaïem [2] trung bình 41 tuổi.

- Giới tính: một số nghiên cứu cho rằng tỷ lệ nam cao hơn nữ, một số nghiên cứu lại chỉ ra rằng nữ cao hơn nam. Vũ Chí Thành [1] nam/ nữ : 1,2/1; McAdams HP nam/nữ 1,3/1. Trong nghiên cứu của chúng tôi tỷ lệ nam/ nữ: 1/1,3; như vậy sự mắc bệnh của nam và nữ là không có sự khác biệt với $\mathrm{p}>0,05$.

\subsection{Triệu chứng}

- Triệu chứng lâm sàng chủ yếu của bệnh cảnh hô hấp: ho, ho máu, đau ngực, khó thở, sốt (bảng 1). Điều đó nói nên việc chẩn đoán và điều trị nhầm là dễ hiểu. Các triệu chứng tương tự trong kết quả nghiên cứu Vũ Chí Thành (2003) [1] nghiên cứu 33 bệnh nhân kén phế quản triệu chứng chủ yếu là đau ngực, sốt, ho khan, ho ra máu, khó thở. Theo Faten Limaïem [2] nghiên cứu kén phế quản trung thất $94 \%$ trường hợp có triệu chứng thì có đến 48,5 \% là đau ngực.

- Chỉ có một trường hợp tình cờ phát hiện, không có triệu chứng khi khám sức khỏe định kỳ, so với một số tác giả khác là rất thấp: Sarper và cộng sự $18 \%$ [3]. Điều đó càng nói lên việc phát hiện và điều trị muôn khi đã có biến chứng.

\subsection{Chẩn đoán hình ảnh}

- Bên tổn thương: Nhìn các con số có vẻ ngực phải chiêm ưu thế. Sử dụng thuật toán so sánh tỷ lệ thì tổn thương bên ngực phải và trái là không có sự khác biệt có ý nghĩa thống kê với $\mathrm{p}=$ 0.445 (Bảng 3). Vũ Chí Thành 2003 [1] gặp bên phải cao hơn bênh trái gấp 2 lần. Philippe Cuypers tỷ lệ phải/ trái: 1,7/1. Trong khi đó kén phế quản trong phổi tỷ lệ gặp bên phải cao hơn bên trái còn kén ở trung thất thì ngược lại tỷ lệ bên trái cao hơn.

- Vị trí kén phế quản gặp chủ yếu trong phổi hơn là trung thất, sự khác biệt có ý nghĩa thống kê $\mathrm{p}<0,05$ (Bảng 3) tương tự một số nghiên cứu khác tỷ lệ kén phế quản trung thất ít gặp hơn so ở phổi: Vũ Chí Thành 2003 [1] 100\% kén phế quản phổi, có lẽ các kén phế quản trung thất chưa được quan tâm tới.

- Hình ảnh kén trên phim XQuang thường quy: chủ yếu là dạng khối mờ đồng nhất, kế đến là dạng kén khí, kén mức dịch khí, khối mờ trong kén,... (Bảng 2) điều đó việc chẩn đoán ban đầu dễ nhầm sang bệnh lý khác khi kết hợp với các triệu chứng lâm sang như lao phổi, u phổi, u trung thất, áp xe phổi,... làm cho việc điều trị thực thụ bị chậm trễ. Sunit R. Patel [4] nghiên cứu 18 trường hợp kén phế quản thấy 17 trường hợp có bất thường trên phim chụp xquang ngực thường quy nhưng không được chẩn đoán. Theo Faten Limaïem[2] trong 27 trường hợp trên phim chụp xquang thường quy thấy 18 trường hợp mờ đồng nhất, 7 trường hợp mức dịch khí, 2 trường hợp xẹp phổi.

- Trên phim CT scanner ngực: Cho hình ảnh kén phế quản rõ ràng hơn so với phim XQuang thường quy, đặc biệt các kén nằm ở đường giữa mà trên xquang thường không nhìn thấy được. Các khối mờ đồng nhất được đo tỷ trọng giúp cho việc chẩn đoán phân biệt giữa khối $\mathrm{u}$ đặc và nang dịch, thậm chí dạng tổn thương kén khí, dịch khí, khối mờ trong kén cũng rõ hơn (Bảng 3). Nhưng việc chẩn đoán xác định các dạng tổn thương kén khí, dịch khí, khối mờ trong kén vẫn dễ nhầm với các bệnh cảnh khác như lao, áp xe, u nấm trong hang lao... khi mà tổ chức phổi xung quanh bị viêm nhiễm lâu ngày làm thay đổi hình dáng ban đầu của kén phế quản. McAdams năm 2000 [5] nghiên cứu hình ảnh kén phế quản trung thất trên phim chụp CTscanner ngực 58 
trường hợp kén phế quản trung thất thấy 25 trường hợp nang dich, 25 trường hợp mô mềm, 2 trường hợp kén khí, 2 trường hợp kén dịch - khí, 2 trường hợp can xi hóa không có mô tả hình ảnh khối mờ trong kén, có lẽ do điều kiện môi trường mà biến chứng nhiễm nấm gặp nhiều ở nước ta.

\section{4. Điều trị}

- Các kén phế quản nằm trong phổi phẫu thuật chủ yếu cắt thùy phổi chứa kén $28 / 30$, có số it $2 / 30$ trường hợp cắt kén bảo tồn phổi. Kén phế quản trung thất $100 \%$ cắt kén nhưng có 1 trường hợp phải cắt thùy phổi phối hợp di tình trạng viêm của phổi kèm theo. 3 trường hợp có kén cả phổi và trung thất thì có 1 trường hợp cắt nguyên kén, 2 trường hợp cắt kén ở trung thất và cắt thùy chứa kén. Cách thức phẫu thuật là phù hợp với tình trạng tổn thương và tình trạng viêm dính kèm theo của phổi. Theo Vũ Chí Thành 2003 [1] $100 \%$ cắt thùy phổi do các kén nằm trong thùy.

- Theo nghiên cứu của Faten Limaïem 32 trường hợp mổ mở 1 trường hợp mổ nội soi lồng ngực. 31 trường hợp cắt kén 1 trường hợp cắt kén từng phần. Theo Philippe Cuypers [6], nghiên cứu 20 trường hợp thì 19 trường hợp mổ mở cắt kén, 1 trường hợp kén phế quản trung thất được mổ nội soi. Theo Sunit R. Patel [4] 22 trường hợp kén phế quản đều mổ mở, 6 trường hợp trong thùy thì 3 trường hợp cắt thùy không điển hình, 3 trường hợp cắt thùy, còn lại kén phế quản trung thất đều cắt kén. Một số tác giả nghiên cứu phẫu thuật nội soi điều trị kén phế quản như: De Giacomo [7] nghiên cứu 30 trường hợp mổ có nội soi hỗ trợ thì có 28 trường hợp thành công cho thấy được một số ưu điểm của mổ nội soi, chỉ có 2 trường hợp phải chuyển mổ mở. Thời gian phẫu thuật thường kéo dài do tình trạng viêm dính của phổi với thành ngực, trung thất, cơ hoành được mô tả khi phẫu thuật, như vậy việc phát hiện và điều trị phẫu thuật sớm sẽ giúp cho phẫu thuật thuận tiện và an toàn hơn cho người bệnh.
- Thời gian nằm viện trung bình cao hơn hẳn so với báo cáo của tác giả Philippe Cuypers [6] thời gian nằm viên trung bình 14,6 ngày, Vũ Chí Thành [1] 13,2 ngày sự khác biệt này không có ý nghĩa thống kê $\mathrm{p}>0,05$.

- Biến chứng trong mổ tỷ lệ thấp và kiểm soát được chủ yếu là chảy máu do viêm dính nhiều shunt mạch tân tạo giữa phổi và thành ngực, một trường hợp phổi viêm dính chắc vào động mạch dưới đòn được xử lý kịp thời tránh được hậu quả đáng tiếc.

- Biến chứng sớm sau mổ thường ít như chảy máu, viêm phổi sau mổ, không có tử vong sau mổ. Các biến chứng muộn khác thường gặp sau rút dẫn lưu màng phổi, chủ yếu ổ dịch khí khu trú (Bảng 5). So với các tác giả khác các biến chứng trong nghiên cứu của chúng tôi nhiều hơn hẳn do tình trạng viêm dính, tổn thương phổi phối hợp: Theo Sunit R. Patel [4] chỉ 1 trường hợp rò khí sau mổ. Theo Vũ Chí Thành [1], biến chứng sau mổ nhẹ và ít: sớm 1 trường hợp chảy máu sau mổ, 1 trường hợp viêm phổi, biến chứng muộn có 3 trường hợp nhiễm trùng vết mổ.

- Khi ra viện 100\% lâm sàng ổn định, x quang ngực phổi nở tốt, một số ít trường hợp có viêm dày màng phổi nhẹ.

\subsection{Kết quả giải phẫu bệnh}

- Giải phẫu bệnh các kén phế quản trung thất đều không có tình trạng bội nhiễm và nấm phát triển. Trong khi đó kén phế quản bội nhiễm và nhiễm nấm đều gặp kén ở phổi. Trong 3 trường hợp kén cả ở phổi và trung thất thì có đến 2 trường hợp kén bị bội nhiễm (Bảng 4). Điều đó càng nói lên sự cần thiết chẩn đoán sớm và can thiệp kịp thời khi chưa có biến chứng. So với nghiên cứu của Vũ Chí Thành [1] chỉ có 1/33 trường hợp nhiễm nấm Aspergillus. Kén phế quản đơn thuần và bội nhiễm thì tương tự như kết quả của chúng tôi. 


\section{KẾT LUẬN}

Kén phế quản là bệnh lý bẩm sinh, nhưng việc chẩn đoàn và điều trị thường muộn khi có biến chứng do vậy việc điều trị phẫu thuật khó khăn và việc bảo tồn phổi với các kén ở phổi gặp hạn chế, để lại nhiều di chứng, biến chứng trong và sau phẫu thuật.

Để tránh các vấn đề trên cần chẩn đoán sớm dựa trên Xquang thường quy, $\mathrm{CT}$ scanner ngực và điều trị triệt để bằng phẫu thuật.

\section{TÀI LIỆU THAM KHẢO}

1. Vũ Chí Thành (2003), Nghiên cứu đặc điểm lâm sàng Xquang của bệnh nhân kén phế quản, Đại học Y Hà Nội, Hà Nội.

2. Limaïem, Faten, Ayadi-Kaddour, Aïda, Djilani, Habiba, et al. (2008), "Pulmonary and mediastinal bronchogenic cysts: a clinicopathologic study of 33 cases", Lung. 186(1), pp. 55-61.
3. Sarper, Alpay, Ayten, Arife, Golbasi, Ilhan, et al. (2003), "Bronchogenic cyst", Texas Heart Institute Journal. 30(2), pp. 105-108.

4. Patel, Sunit R, Meeker, David P, Biscotti, Charles V, et al. (1994), "Presentation and management of bronchogenic cysts in the adult", CHEST Journal. 106(1), pp. 79-85.

5. McAdams, H. P., Kirejczyk, W. M., Rosado-de-Christenson, M. L., et al. (2000), "Bronchogenic cyst: imaging features with clinical and histopathologic correlation", Radiology. 217(2), pp. 441-6.

6. Cuypers, Philippe, De Leyn, Paul, Cappelle, Lieve, et al. (1996), "Bronchogenic cysts: a review of 20 cases", European journal of cardio-thoracic surgery. 10(6), pp. 393-396.

7. De Giacomo, Tiziano, Diso, Daniele, Anile, Marco, et al. (2009), "Thoracoscopic resection of mediastinal bronchogenic cysts in adults", European Journal of Cardio-Thoracic Surgery. 36(2), pp. 357-359. 